REFERENCES:

Table 1.

\begin{tabular}{|c|c|c|c|c|c|c|c|c|c|c|c|c|c|c|c|}
\hline & $\begin{array}{l}M i-2 \\
(n=5)\end{array}$ & $\begin{array}{l}\text { PL-7 } \\
(n=6)\end{array}$ & $\begin{array}{l}\text { PL-12 } \\
(n=4)\end{array}$ & $\begin{array}{l}\text { Jo-1 } \\
(n=6)\end{array}$ & $\begin{array}{l}\text { MDA5 } \\
(n=1)\end{array}$ & $\begin{array}{c}\text { antiRo52 } \\
(n=57)\end{array}$ & $\begin{array}{l}\text { SRP } \\
(n=3)\end{array}$ & $\begin{array}{l}\text { Scl-70 } \\
(n=12)\end{array}$ & $\begin{array}{l}\text { CENP } \\
(n=14)\end{array}$ & $\begin{array}{l}\mathrm{Th}( \\
\mathrm{n}=2)\end{array}$ & $\underset{(n=14)}{K u}$ & $\begin{array}{l}\text { Fibrilarina } \\
\quad(n=2)\end{array}$ & $\begin{array}{c}\text { PM-Scl75/100 } \\
(n=23)\end{array}$ & $\begin{array}{c}\text { NOR90 } \\
(n=8)\end{array}$ & $\begin{array}{c}\text { RNA pol } \\
(n=2)\end{array}$ \\
\hline ILD & 0 & $4(66.7)$ & $4(100)$ & $3(50)$ & $1(100)$ & 19 (33.3) & 0 & 7 (58.3) & $1(7.1)$ & 0 & $7(50)$ & $1(50)$ & 9 (39.1) & $5(62.5)$ & 0 \\
\hline Cancer & $1(20)$ & 0 & 0 & 0 & 0 & $6(10.5)$ & 1 (33.3) & 0 & 0 & 0 & $1(7.1)$ & 0 & 0 & 0 & 0 \\
\hline
\end{tabular}

FIGURE 1

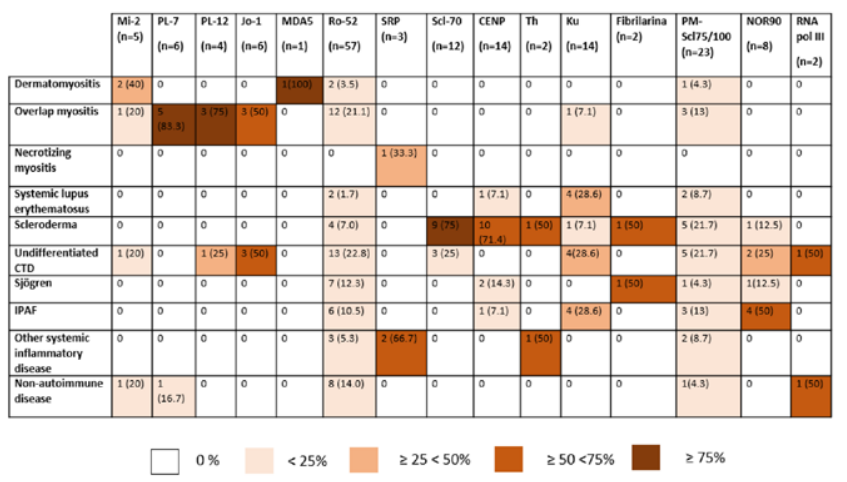

Disclosure of Interests: None declared

DOI: 10.1136/annrheumdis-2021-eular.1724

\section{AB0431 EXPLORING THE UTILITY OF THE AMERICAN COLLEGE OF RHEUMATOLOGY (ACR) CRISS IN PATIENTS WITH DIFFUSE CUTANEOUS SYSTEMIC SCLEROSIS}

F. Del Galdo ${ }^{1}$, O. Distler ${ }^{2}$, C. Denton ${ }^{3}$, Y. Allanore ${ }^{4}$, D. Wachtlin ${ }^{5}$, M. Alves ${ }^{6}$, D. Khanna ${ }^{7}{ }^{1}$ University of Leeds, Leeds Institute of Rheumatic and Musculoskeletal Medicine and NIHR Biomedical Research Centre, Leeds, United Kingdom; ${ }^{2}$ University Hospital Zurich, Department of Rheumatology, Zurich, Switzerland; ${ }^{3}$ University College London Division of Medicine, Centre for Rheumatology and Connective Tissue Diseases, London, United Kingdom; ${ }^{4}$ Descartes University, APHP, Cochin Hospital, Department of Rheumatology A, Paris, France; ${ }^{5}$ Boehringer Ingelheim Pharma GmbH \& Co. KG, Biostatistics + Data Sciences, Ingelheim, Germany; ${ }^{6}$ Boehringer Ingelheim International GmbH, TA Inflammation Med, Ingelheim, Germany; ${ }^{7}$ University of Michigan, Department of Medicine, Ann Arbor, United States of America

Background: The ACR Composite Response Index in diffuse cutaneous Systemic Sclerosis (CRISS) was developed to measure the probability of improvement in response to treatment in patients with early diffuse cutaneous SSC (dcSSc), accounting for new/worsening cardiopulmonary involvement and/or renal crisis, and changes in modified Rodnan skin score, forced vital capacity, health assessment questionnaire disability index, and patient's and physician's global impressions. In patients with SSc-ILD, treatment response may be reflected as slower progression, stabilisation or improvement.

Objectives: Using data from patients with dcSSc and ILD in the placebo group of the SENSCIS trial, we analysed the probability of improvement using the ACR CRISS score at week 52 . We also evaluated whether the CRISS numerator could provide information on the spectrum of responses in this patient population

Methods: The SENSCIS trial enrolled subjects with SSc-ILD with onset of first non-Raynaud symptom $\leq 7$ years before screening, FVC $\geq 40 \%$ predicted, and fibrotic ILD $\geq 10 \%$ extent on an HRCT scan. Subjects on prednisone $\leq 10 \mathrm{mg} /$ day (or equivalent) and/or stable therapy with mycophenolate or methotrexate were allowed to participate. Subjects were randomised to receive nintedanib or placebo. Subjects were not randomised by use of mycophenolate. In patients randomised to receive placebo who had dcSSc and/ or mRSS $>15$ at baseline, we analysed the ACR CRISS and its numerator at week 52 in subgroups by use of mycophenolate at baseline. Analyses were exploratory and descriptive.

Results: Of 117 analysed subjects in the placebo group who had dcSSc and/or mRSS $>15$ at baseline, 60 (51.3\%) were taking mycophenolate at baseline. Compared with patients not taking mycophenolate at baseline, those taking mycophenolate had a lower mean age (48.4 [SD 11.8] vs 53.1 [13.4] years), lower mean FVC \% predicted (68.8 [17.0] vs $73.0[14.6])$, and a greater proportion were female $(76.7 \%$ vs $71.9 \%)$; median time since first onset of non-Raynaud symptom was similar ( 3.9 vs 4.5 years, respectively) as was mean (SD) mRSS (16.5 [7.7] vs 15.9 [8.0], respectively). One patient (taking mycophenolate at baseline) had limited cutaneous SSc. At week 52, median (Q1, Q3) ACR CRISS score was $0.036(0.001,0.601)$ in subjects taking mycophenolate and $0.002(0.000$, 0.112 ) in subjects not taking mycophenolate at baseline, and mean (SD) ACR CRISS score was $0.28(0.37)$ in subjects taking mycophenolate and $0.16(0.31)$ in subjects not taking mycophenolate at baseline (Figure 1). In these groups, respectively, $25.0 \%$ and $14.0 \%$ of subjects had CRISS score $>0.6$ (considered improved) at week 52 . The CRISS numerator provided a broader distribution of response values, but was not informative in this patient population.

Conclusion: In exploratory analyses, among subjects with dcSSc and ILD who received placebo in the SENSCIS trial, the proportion considered improved at week 52 based on ACR CRISS score was numerically greater in patients taking than not taking mycophenolate at baseline. There remains a need for composite scores that provide better interpretation of the magnitude of response in patients with SSc.

\section{Figure. Box-and-whisker plot of CRISS score at week 52 in subjects with SSC-ILD with dcSSC and/or mRSS > 15 at baseline in the
placebo group of the SENSCIS trial by use of mycophenolate at baseline}

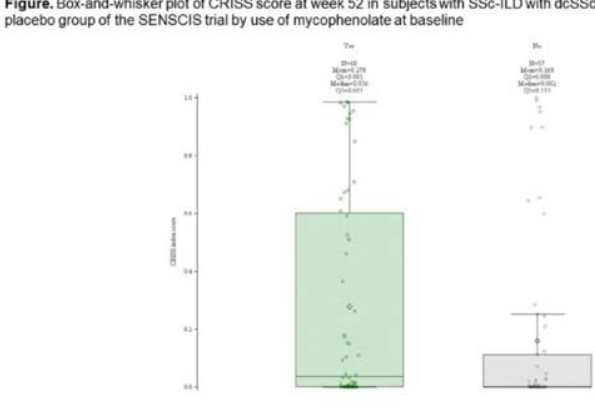

Acknowledgements: The SENSCIS trial was funded by Boehringer Ingelheim. Medical writing support was provided by FleishmanHillard Fishburn, London, UK. The authors meet criteria for authorship as recommended by the International Committee of Medical Journal Editors (ICMJE).

Disclosure of Interests: Francesco Del Galdo Speakers bureau: Actelion and AstraZeneca, Consultant of: Actelion, AstraZeneca, Boehringer Ingelheim, Capella BioScience, ChemomAb and Mitsubishi Tanabe Pharma, Grant/research support from: Capella BioScience, Kymab and Mitsubishi Tanabe Pharma, Oliver Distler Consultant of: AbbVie, Acceleron Pharma, Amgen, AnaMar, Arxx Therapeutics, Baecon Discovery, Bayer, Blade Therapeutics, Boehringer Ingelheim, ChemomAb, Corbus, CSL Behring, Galapagos NV, GlaxoSmithKline, Glenmark Pharmaceuticals, Horizon (Curzion) Pharmaceuticals, Inventiva, IQVIA, Italfarmaco, iQone Kymera Therapeutics, Lilly, Medac, Medscape, Merck Sharp \& Dohme, Mitsubishi Tanabe Pharma, Novartis, Pfizer, Roche, Sanofi, Serodapharm, Target Bioscience, Topadur Pharma and UCB, Grant/research support from: Kymera Therapeutics and Mitsubishi Tanabe Pharma, Christopher Denton Speakers bureau: Boehringer Ingelheim, Corbus, Janssen, and Mallinckrodt Pharmaceuticals, Consultant of: Acceleron Pharma, Arxx Therapeutics, Bayer, Boehringer Ingelheim, Corbus, CSL Behring, Galapagos NV, GlaxoSmithKline, Horizon Therapeutics, Janssen, Mallinckrodt Pharmaceuticals, Roche, Sanofi and UCB, Grant/research support from: Arxx Therapeutics, GlaxoSmithKline and Servier, Yannick Allanore Consultant of: Boehringer Ingelheim, Medsenic, Menarini and Sanofi, Grant/research support from: Alpine Pharmaceuticals, Daniel Wachtlin Employee of: Currently an employee of Boehringer Ingelheim, Margarida Alves Employee of: Currently an employee of Boehringer Ingelheim, Dinesh Khanna Shareholder of: Eicos Sciences, Inc. (less than 5\%), Consultant of: Acceleron Pharma, Actelion, AbbVie, Amgen, Bayer, Boehringer Ingelheim, CSL Behring, Corbus, Gilead Sciences, Galapagos NV, Genentech/Roche, GlaxoSmithKline, Horizon Therapeutics, Merck, Mitsubishi Tanabe Pharma, Sanofi-Aventis and United Therapeutics, Grant/research support from: Bayer, Bristol-Myers Squibb, Horizon Therapeutics, Immune Tolerance Network, National Institutes of Health and Pfizer, Employee of: Chief Medical OfficerCiviBioPharma/Eicos Sciences, Inc.

DOI: 10.1136/annrheumdis-2021-eular.1760 